\title{
A smart monitoring and controlling for agricultural pumps using LoRa IOT technology
}

\author{
Aktham Hasan Ali ${ }^{1}$, Raad Farhood Chisab ${ }^{2}$, Mohannad Jabbar Mnati ${ }^{3}$ \\ ${ }^{1,3}$ Department of Electronic Technology, Institute of Technology Baghdad, \\ Middle Technical University, Baghdad, Iraq \\ ${ }^{2}$ Department of Electrical Technology, Technical Institute Kut, \\ Middle Technical University, Baghdad, Iraq \\ ${ }^{3}$ Department of Electrical Energy, Metals, Mechanical Constructions and Systems, \\ Ghent University, Gent, Belgium
}

\begin{tabular}{l}
\hline \hline Article Info \\
\hline Article history: \\
Received Aug 12, 2018 \\
Revised Nov 20, 2018 \\
Accepted Dec 3, 2018
\end{tabular}

\section{Keywords:}

Agricultural pumps

IOT

LoRa technology

MIT app inventor 2

Smart monitoring

\begin{abstract}
Controlling electrical pumps on farms can be problematic, especially if there are a small number of people managing or working on huge areas of land and if the provision of electricity is not consistent. Therefore, further techniques for the management of plant irrigation on this type of land are being invented to make the process of irrigation easier. In this paper, a new intelligent device is designed and utilized to control the operation of irrigation pumps using a robust method of communication to transfer information at long distances, for the lowest cost, and the longest battery life. This technology is called LoRa (Long Range) communication, which is a low-power technology. The unit consists of two circuits: the first one is for switching the pumps ON and OFF, while the second one controls and monitoring the work of the pumps. Monitoring of the pumps can also be carried out through smart phones by measuring the voltage. The most important features of this new design are its intelligent control for long distances, cheap price, and a long operational life of more than five years. The goal of this paper is to help farmers by designing and manufacturing a remote-control system that switches irrigation pumps on and off using LoRa technologies.
\end{abstract}

Copyright $\odot 2019$ Institute of Advanced Engineering and Science. All rights reserved.

\section{Corresponding Author:}

Mohannad Jabbar Mnat,

Department of Electrical Energy,

Metals, Mechanical Constructions and Systems,

Ghent University, Gent, Belgium.

Email: mohannad.mnati@ugent.be

\section{INTRODUCTION}

The electricity sector in our present life is our lifeblood and the secret of its permanence. In some places, the agricultural sector is suffering from continuous interruptions of electricity, especially in daylight hours when farmers carry out irrigation operations on farms, causing a shortage of water to process the fields, especially for farmers who live a distance from their farms [1-2].

Our goal in this research is to help these farmers by designing and manufacturing a remote-control system that runs and shuts down irrigation pumps through the use of modern technology called LoRa communication [3].

LoRa (Long Range) represents the physical layer or the wireless modulation used to build peakrange communication connexion. It is built on "chirp spread spectrum modulation" and has similar small energy features to FSK modulation. "Chirp spread spectrum" was applied in army and galaxy communication years ago for more widespread communication distance strength against interfering. LoRa is the primary cheap application for marketable usage [4-7]. The benefit of LoRa is its extended distance ability. It has a 
more economical connection than any other uniform communication technique. The general specification of LoRa technology can be summarised as: "Single Operating Voltage: $2.1 \mathrm{~V}$ to $3.6 \mathrm{~V}$ (3.3V typical), Temperature Range: $-40^{\circ} \mathrm{C}$ to $+85^{\circ} \mathrm{C}$, Low-Power Consumption, Programmable RF Communication Bit Rate up to $300 \mathrm{kbps}$ with FSK Modulation, 10937 bps with LoRa Technology Modulation, Integrated MCU, EUI-64 Node Identity Serial EEPROM, Radio Transceiver with Analogue Front End, Matching Circuitry, 14 GPIOs for Control and Status, Shared with 13 Analog Inputs, Low-Power Long Range Transceiver Operating in the $433 \mathrm{MHz}$ and $868 \mathrm{MHz}$ Frequency Bands, High Receiver Sensitivity: Down to -146 dB, up to $15 \mathrm{~km}$ Coverage at Suburban and up to $5 \mathrm{~km}$ Coverage in an Urban Area" [8-11].

The "RF LoRa physical layer" works as a method for modulation of the "spread spectrum". The LoRa modulation pattern works as "wide-band linear frequency modulated pulses". The amount of frequency growth or reduction in the above period is worked to encrypt the information being spread, i.e. a method of "chirp modulation". This method of modulation supports LoRa structures to demodulate information that are $20 \mathrm{~dB}$ lower than the ground noise once the demodulation is joined with "forward error correction FEC". It can be said that the connection economical for a LoRa structure should deliver an enhancement of further than $25 \mathrm{~dB}$ after it is related to a traditional FSK scheme [12-14].

A variation of bandwidths exists such as: "7.8 kHz; $10.4 \mathrm{kHz} ; 15.6 \mathrm{kHz} ; 20.8 \mathrm{kHz} ; 31.2 \mathrm{kHz} ; 41.7$ $\mathrm{kHz} ; 62.5 \mathrm{kHz} ; 125 \mathrm{kHz} ; 250 \mathrm{kHz}$; and $500 \mathrm{kHz}$ ". The essential bandwidth is designated providing information necessities in addition to connection situations. The amount of power taken inside "LoRa RF physical layer" is changeable. The power amount taken by LoRa is related to the data rate required and the circumstances of the connection. A procedure calculates the essential power amount. The spread power is usually reduced slightly from the extreme required to provide rapid communications. Within that technique the battery-operated lifetime is raised. The usage of the "chirp spread spectrum" technique allows communications through miscellaneous information that is never affected by other signals [15-16].

\section{IRRIGATION SYSTEM BASED ON LoRa COMMUNICATION}

In our paper, a system was designed and implemented to monitor and control the running and switching on and off of irrigation pumps for farmers living in areas a distance from their land. The device is designed and manufactured using the latest technology in modern communications (LoRa Technology). The advantages of this technology is its small size, cheap price, and its ability to control devices remotely up to $10 \mathrm{~km}$ without the use of towers for communication and other additional costs. This device operates on a battery that works for more than five years and consumes a low level of power by these devices. LoRa technology devices have a range from $1 \mathrm{~km}$ to more than $10 \mathrm{~km}$. The $2.8 \mathrm{~km}$ range was used in our paper. As shown in Figure 1, the types of applications that use LoRa technology

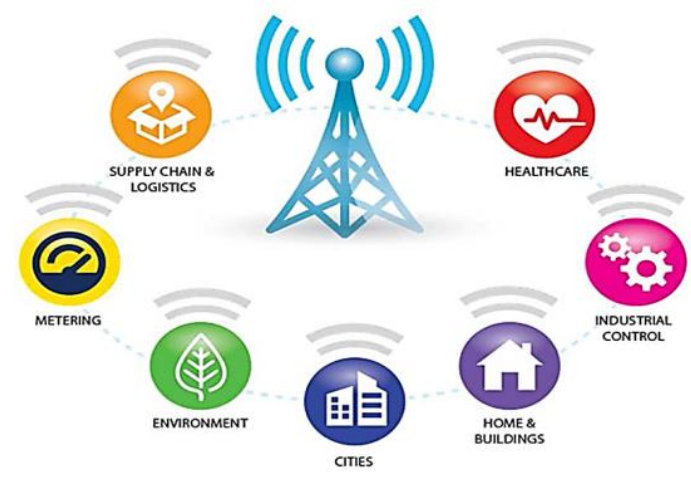

Figure 1. The types of applications that use LoRa technology

The smart device, which is manufactured as in Figure 2, consists of two main circuits: the first piece (control circuit) connects at the input of the electric power of the pump and its location in the farms. The second piece (monitoring circuit) is often found in homes or in places of control. We can consider that the two circuits are for sending and receiving at the same time.

The first circuit (control circuit) consists of these main parts: a LoRa ESP32, for the purpose of sending and receiving data, a special circuit to monitor the electrical voltage in the network, and finally a special circuit to control the running of and for turning off the electric pump. 
The second circuit consists of the LoRa device (the same type of device located in the first circuit), two keys for the purpose of running and switching off the electrical pump, and a small LCD screen to monitor the system. Another feature of the device is that it can be monitored and controlled by the use of a special program designed for this purpose. It is installed on smart phones that run on an Android system; it can be connected to the second circuit via Bluetooth and has a range of more than 10 metres. The device was operated and tested and proved to be very efficient in terms of sending and receiving data between the two main parts.

\section{SPECIFICATION OF THE SYSTEM}

In this section, we will explain the main parts of the manufacturing intelligent system that controls and monitors the irrigation pumps. As shown in Figure 2, the system is divided into the following parts:

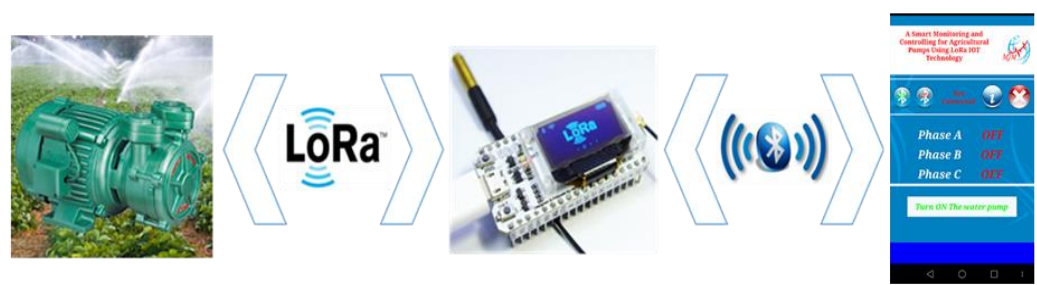

Figure 2. The control system for irrigation pumps

\subsection{The Control Circuit}

The control circuit is the main circuit of the intelligent device designed in this paper, which connects directly to the input of the power supply designated for the operation of the irrigation pump. This can be divided into three sections linked to each other and constitute a total so-called control circuit:

a) Transmitter and Receiver circuit

The transmitter and receiver circuit shown in Figure 3 is the main circuit or main part of the control circuit, which consists of LoRa ESP32 wireless technology (the latest type of long-range wireless communication) with transmission and delivery ranges of more than $10 \mathrm{~km}$. Table 1 represents the main and most important characteristics of the technology used in this paper.

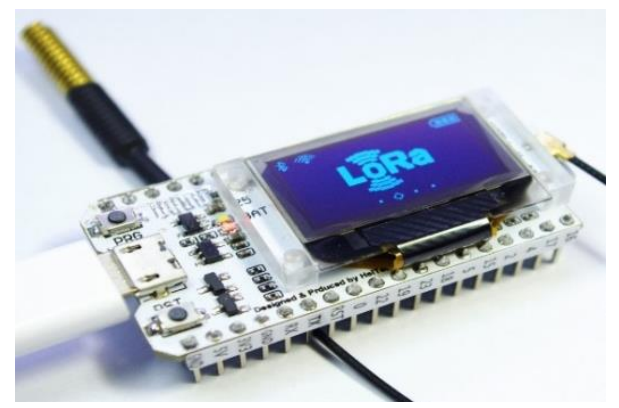

Figure 3. The LoRa communication system (LoRa ESP32)

Table 1. The Main Characteristics of LoRa Wireless Communications Technology (LoRa ESP32)

\begin{tabular}{cc}
\hline Parameter & Value \\
\hline Frequency & $240 \mathrm{MHZ}$ \\
Type of micro-Processor & "Tensilica LX6 Dual Core" \\
Major Chip & "ESP32" \\
Chip of LoRa & "SX1276" \\
Communication Distance & Up to 2.8KM \\
Computing Capacity & Up to 600DMIPS \\
Operating Voltage & $3.3-7 \mathrm{~V}$ \\
Operating Temperature & -40 to $-90^{\circ} \mathrm{C}$ \\
USB Adapter Chip & $\mathrm{CP} 2102$ \\
\hline
\end{tabular}

Indonesian J Elec Eng \& Comp Sci, Vol. 13, No. 1, January 2019 : 286 - 292 
b) The Voltage Monitoring Circuit

The second part of the control circuit is the monitoring circuit as shown in Figure 3. this device indicates if the current in the primary board can run irrigation motor or the current is cut. The main voltage, which is $230 \mathrm{~V}$ to $5 \mathrm{~V}$, is converted by high-value resistance and there is an electrical circuit between the current of the main board and the controller circuit located within the LoRa technology. Figure 4(a) shows the final link of this circuit. Figure 4(b) exhibits a diagram of the electronic circuit.

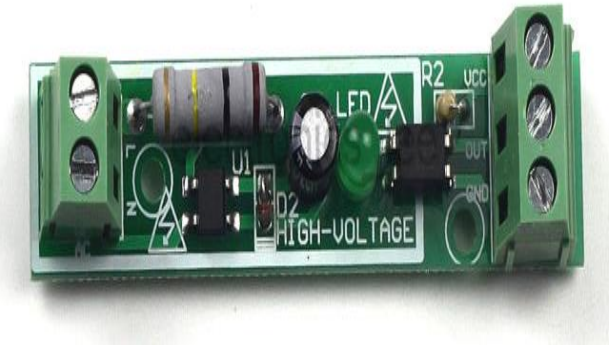

(a)

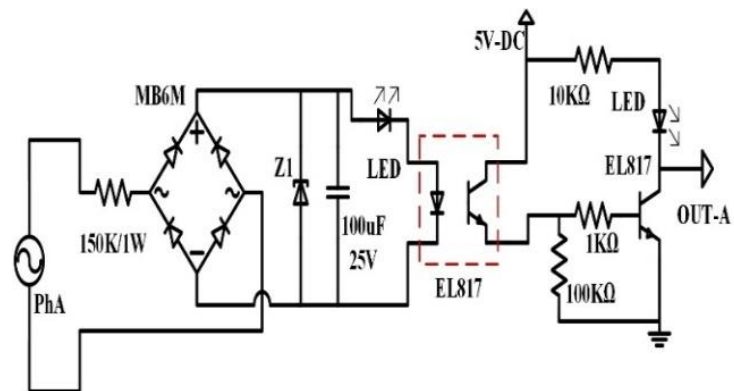

(b)

Figure 4. Voltage mesurring circuit: (a) singular phase circuit and (b) the circuit diagram of the measuring circuit

\section{c) The ON-OFF Control Circuit}

The third part of the control circuit is responsible for the running of and the turning off of the pump based on guidance received from the benefits of the "running and turning off system". This circuit is illustrated in Figure 5, which consists of a 230-volt voltage control switch that connects with the existing controller with LoRa technology via the transistor for running and shutting down the system.

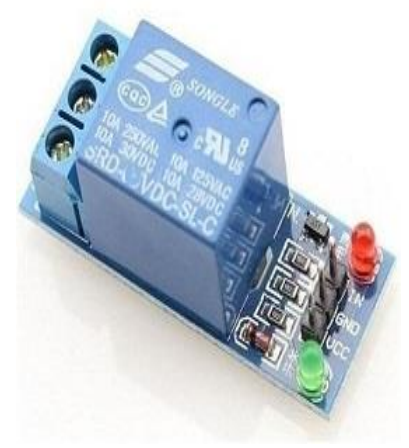

(a)

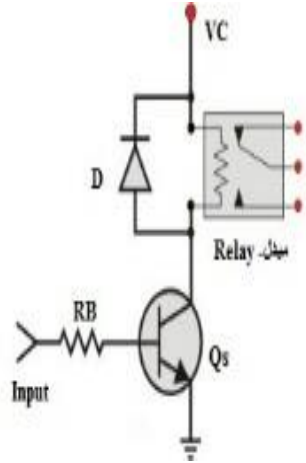

(b)

Figure 5. The control circuit: (a) ON-OFF control circuit and (b) a diagram of the control circuit

\subsection{The Control Circuit}

This second main part, which was developed close to the user, was in the house or in place of monitoring. This part consists of the same parts mentioned in paragraph 4.1.A. (LoRa ESP32), in addition to being programmed to enable the user to control the system via the smart device after the interception between the smart device and Bluetooth technology; a special program is prepared for this purpose.

The programs used in this research are divided into two parts. The first one is the program of controllers for LoRa transmission and receiving technologies, based on the open-source programs that are available on Android. Figure 6 shows the flow chart of the transmitter circuit and the receiving circuit.

The second program, the remote-control program, was designed for this purpose using the program (MIT app inventor 2), an open-source program supported by Google. Figure 7 shows the main interface of the program "MIT app inventor 2", with all its features to design and implement programs for Android smart devices. 


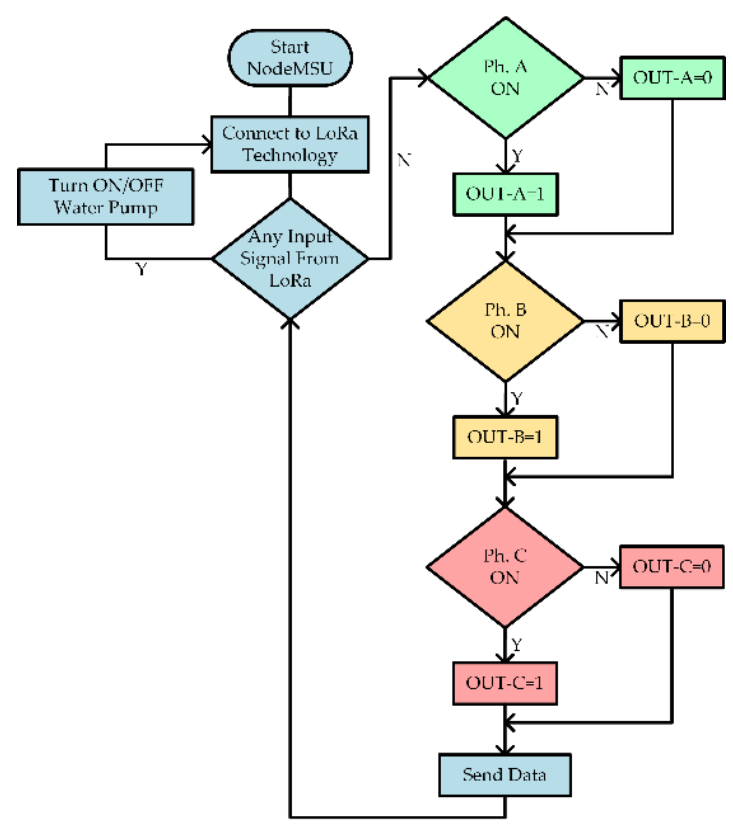

(a)

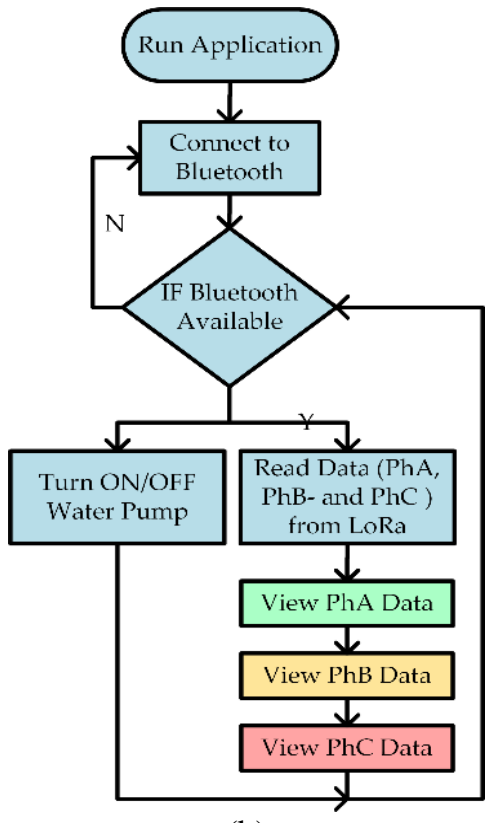

(b)

Figure 6. The flowchart of the full system: (a) the transmitter flowchart and (b) the receiving flowchart

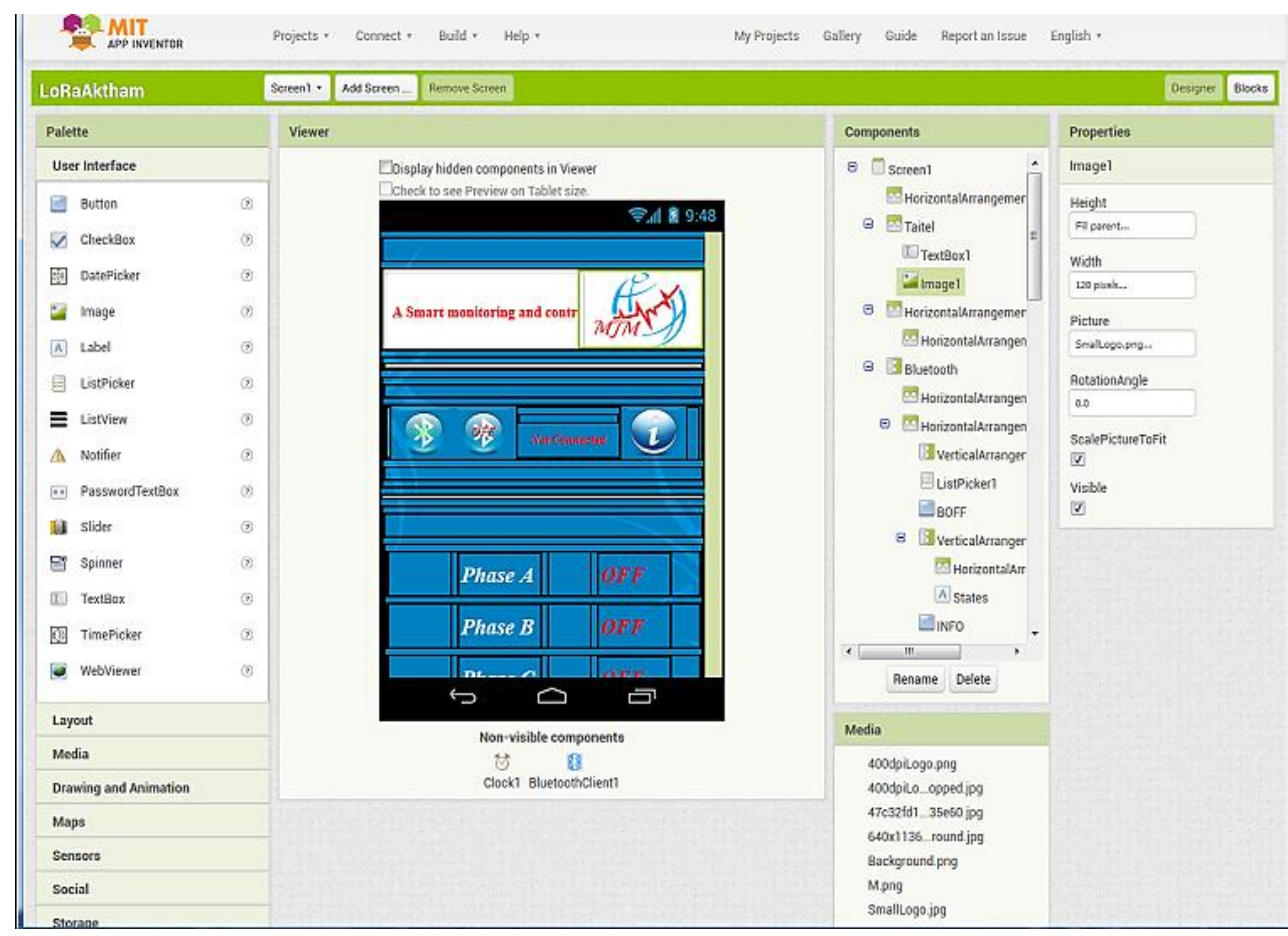

Figure 7. The main interface of the program (MIT app inventor 2)

\section{THE COMPREHENSIVE FINAL SYSTEM}

This part is divided into two main areas: the hardware and the software control program. Figure 8(a) illustrates the final designed circuit that connects to the water pump. It consists of the most important and latest part, which is the LoRa ESP32 wireless technology, plus a three-phase voltage control circuit with a circuit to run and turn off the electrical pump. Figure 8(b) shows the second class of the LoRa ESP32 wireless technology, which is either in the farmhouse or other beneficiary, or in a place designated for control and monitoring purposes. 
Figure 9 explains the final program, which is designed and implemented for the purpose of controlling. This program is installed on smart devices and through which the control of the agricultural pump through the smart phones is conducted. This process is done with the device that operates on the Android system after communicating with the second circuit (LoRa ESP32) via Bluetooth technology t more than 10 metres away from the second piece in the house or in the control and monitoring area. Figure 9(a) shows that the smart device is not connected via Bluetooth with the second control piece. Figure 9(b) shows the smart device connection with the second piece, but there is no electrical power in the field or farm. Figure 9(c) shows that the phone is connected with some capacity but the agricultural pump has not yet been operated; finally, Figure 9(d) shows that the pump works with the electric power of the three phases.

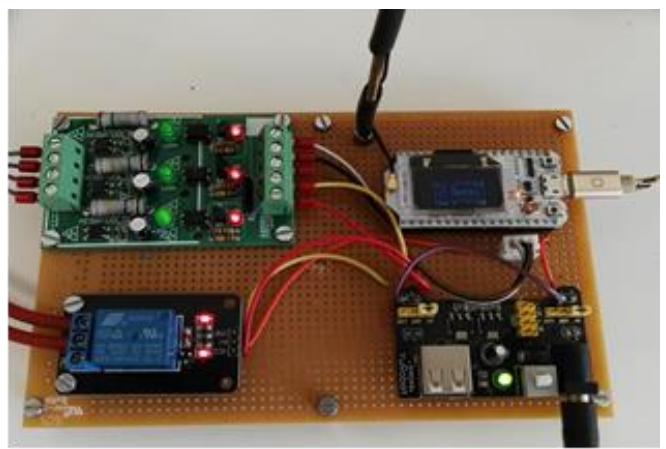

(a)

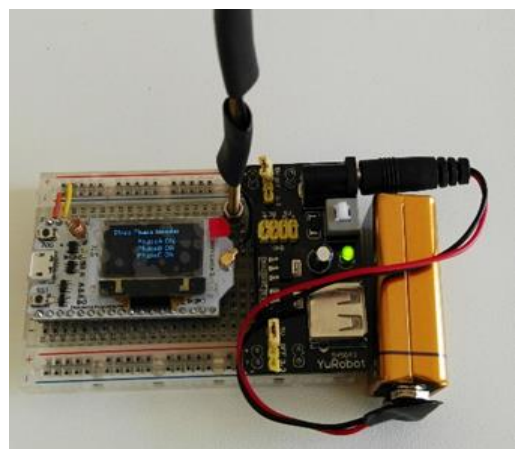

(b)

Figure 8. The practical system: (a) the operation circuit at the pump and (b) the practical circuit in the control centre or the house

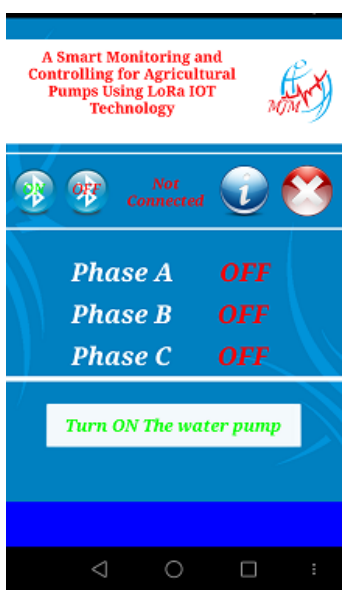

(a)

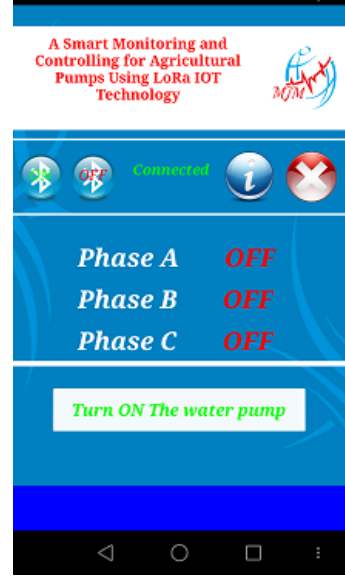

(b)

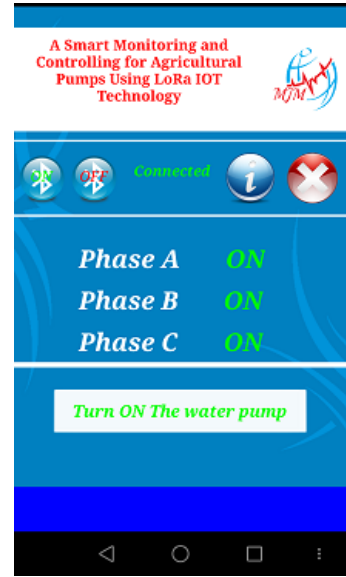

(c)

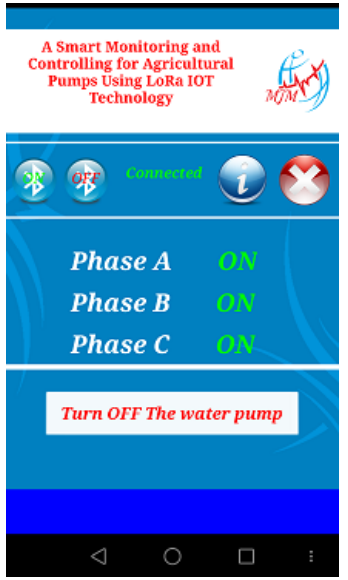

(d)

Figure 9. The final program for monitoring and controlling (a) before the Bluetooth connection (b) After Bluetooth connection but no electrical power (c) After the Bluetooth connection and the power is present but the pump does not work and (d) After the Bluetooth connection and the electrical power is present and the pump is working

\section{CONCLUUSION}

In this paper, a smart system was designed and implemented to monitor and operate agricultural pumps on farms using a smart and modern technique, namely LoRa technology (LoRa ESP32), the latest technology in wireless communications. This technique is used to transmit longdistance signals without additional fees or the use of towers. The battery life is long because of the low consumption of electricity. The system can be controlled by Bluetooth technology using a special program installed on smart devices running on the Android system. The circuit (the manufacturing system) proved its efficiency in the work when it is applied practically inside the university laboratory. 


\section{REFERENCES}

[1] M. Monica Subashini, Sreethul Das, Soumil Heble, Utkarsh Raj and R Karthik, "Internet of Things Based Wireless Plant Sensor for Smart Farming”, Indonesian Journal of Electrical Engineering and Computer Science, Vol. 10, No. 2, May 2018, pp. 456-468, ISSN: 2502-4752, DOI: 10.11591/ijeecs. v10.i2. pp456-468, Journal homepage: http://iaescore.com/journals/index.php/ijeecs

[2] J. K. Abed and A. Info, "Smart Monitoring System of DC to DC Converter for Photovoltaic Application," vol. 9, no. 2, pp. 722-729, 2018.

[3] M. J. Mnati, A. Van den Bossche, and R. Chisab, "A Smart Voltage and Current Monitoring System for Three Phase Inverters Using an Android Smartphone Application,” Sensors, vol. 17, no. 4, p. 872, 2017.

[4] MD. Reza Ranjbar and Aisha H. Abdalla, "Development of an Autonomous Remote Access Water Quality Monitoring System", Indonesian Journal of Electrical Engineering and Computer Science, Vol. 8, No. 2, November 2017, pp. $467 \sim 474$, DOI: 10.11591/ijeecs.v8.i2.pp467-474, Journal homepage: http://iaescore.com/journals/index.php/ijeecs

[5] Raad Farhood Chisab and C. K. Shukla, "The Downlink 4G-LTE in Fading Channel Based on the Multiwavelet Transform", IEEE Sixth International Conference on Computational Intelligence and Communication Networks (CICN 2014), pp. 233-236, 2014.

[6] S. I. Samsudin, S.I.M. Salim, K. Osman, S. F. Sulaiman and M. I. A. Sabri, "A Smart Monitoring of a Water Quality Detector System", Indonesian Journal of Electrical Engineering and Computer Science, Vol. 10, No. 3, June 2018, pp. 951 958, ISSN: 2502-4752, DOI: 10.11591/ijeecs.v10.i3.pp951-958, Journal homepage: http://iaescore.com/journals/index.php/ijeecs

[7] M. J. Mnati, R. F. Chisab and A. Van den Bossche, "A smart distance power electronic measurement using smartphone applications," 2017 19th European Conference on Power Electronics and Applications (EPE'17 ECCE Europe), Warsaw, 2017, pp. P.1-P.11. doi: 10.23919/EPE17ECCEEurope.2017.8099394.

[8] Teddy Surya Gunawan, Intan Rahmithul Husna Yaldi, Mira Kartiwi, Nanang Ismail, Nor Farahidah Za'bah, Hasmah Mansor and Anis Nurashikin Nordin, "Prototype Design of Smart Home System using Internet of Things", Indonesian Journal of Electrical Engineering and Computer Science, Vol. 7, No. 1, July 2017, pp. 107 -115, DOI: 10.11591/ijeecs.v7.i1.pp107-115, Journal homepage: http://iaescore.com/journals/index.php/ijeecs

[9] LoRa Alliance. White Paper: "A Technical Overview of Lora and Lorawan", The LoRa Alliance: San Ramon, CA, USA, 2015.

[10] Muhammad Khairie Idham Abd Rahman, Mohamad Shukri Zainal Abidin, Salinda Buyamin, Mohd Saiful Azimi Mahmud, "Enhanced Fertigation Control System Towards Higher Water Saving Irrigation", Indonesian Journal of Electrical Engineering and Computer Science, Vol. 10, No. 3, June 2018, pp. 859-866 ISSN: 2502-4752, DOI: 10.11591/ijeecs.v10.i3.pp859-866, Journal homepage: http://iaescore.com/journals/index.php/ijeecs

[11] Mnati,MJ, Hasan,A, Bozalakov,DV, Bossche,AV. Smart monitoring and controlling of three phase photovoltaic inverter system using lora technology. 6th Eur. Conf. Ren. Energy Sys. 25-27 June 2018, Istanbul, Turkey.

[12] Rathod, N., Jain P.; Subramanian R., Yawalkar S., Sunkenapally M., Amrutur B. and Sundaresan, R., "Performance analysis of wireless devices for a campus-wide IOT network", 13th International Symposium on Modeling and Optimization in Mobile, Ad Hoc, and Wireless Networks (WiOpt2015), Mumbai, India, 25-29 May 2015; pp. 84-89.

[13] M. Monica Subashini, Sreethul Das, Soumil Heble, Utkarsh Raj and R Karthik, "Internet of Things Based Wireless Plant Sensor for Smart Farming", Indonesian Journal of Electrical Engineering and Computer Science, Vol. 10, No. 2, May 2018, pp. 456-468, ISSN: 2502-4752, DOI: 10.11591/ijeecs.v10.i2.pp456-468, Journal homepage: http://iaescore.com/journals/index.php/ijeecs

[14] Petajajarvi J., Mikhaylov K., Roivainen A., Hanninen, T. and Pettissalo M., "On the coverage of lpwans: Range evaluation and channel attenuation model for LoRa technology", 14th International Conference on ITS Telecommunications (ITST2015), Copenhagen, Denmark, 2-4 December 2015; pp. 55-59.

[15] Bor M., Vidler J.E., Roedig U., "Lora for the Internet of Things", International Conference on Embedded Wireless Systems and Networks (EWSN '16), TU Graz, Austria, 15-17 February 2016; pp. 361-366.

[16] Nolan KE, Guibene W and Kelly MY, "An evaluation of low power wide area network technologies for the Internet of Things", IEEE international wireless communications and mobile computing conference (IWCMC 2016), Paphos, Cyprus, 5-9 September 2016, pp.439-444.

\section{BIOGRAPHIES OF AUTHORS}

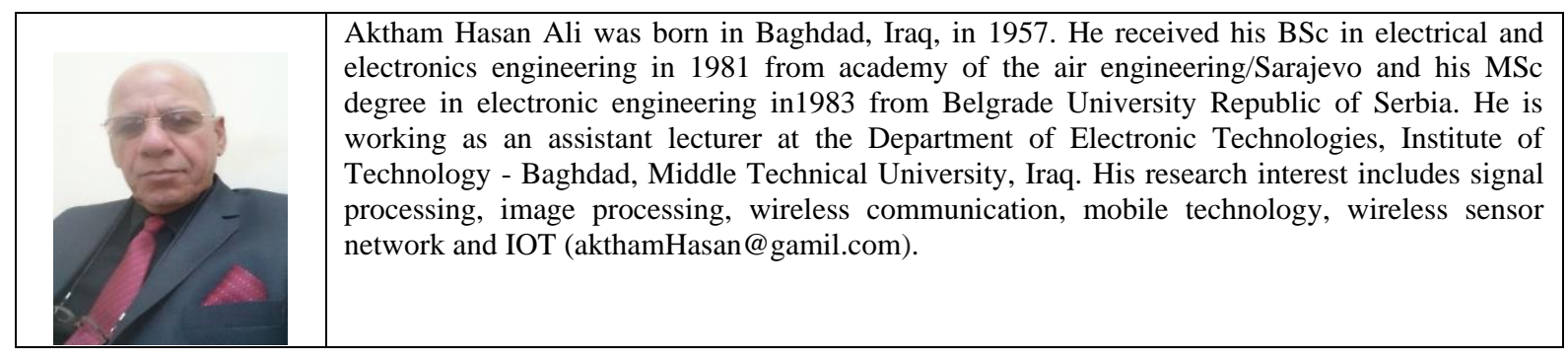

Indonesian J Elec Eng \& Comp Sci, Vol. 13, No. 1, January 2019 : 286 - 292 


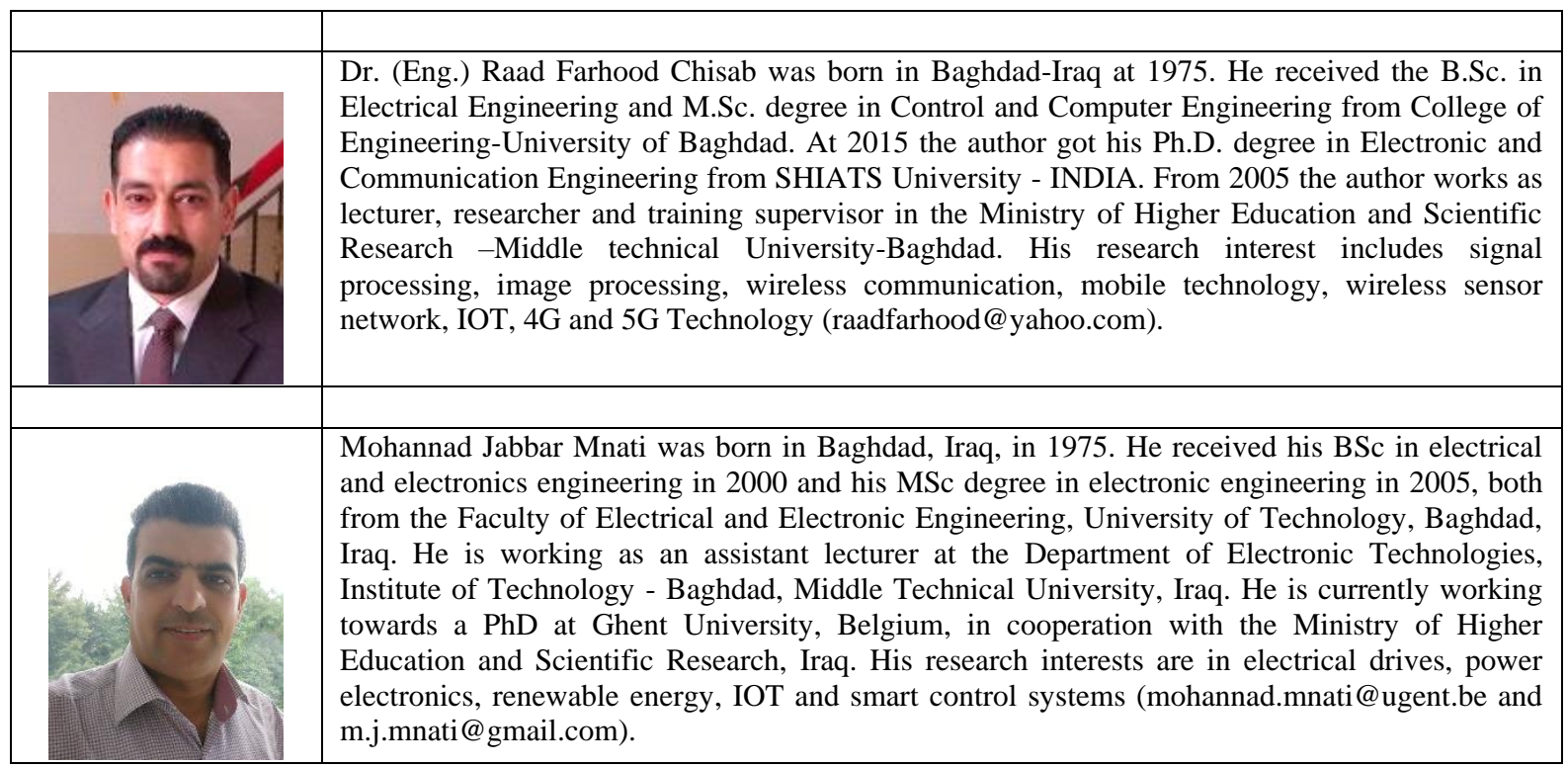

